\title{
EM BUSCA DAS JUSTIFICATIVAS EMPRESARIAIS PARA AS INICIATIVAS AMBIENTAIS DAS EMPRESAS BRASILEIRAS LÍDERES NA PUBLICAÇÃO DE RELATÓRIOS DE SUSTENTABILIDADE
}

\author{
Larissa Gomes da Silva Cardoso \\ Mestre em Engenharia de Produção pela Universidade Federal Fluminense - UFF \\ Mestre em Administração pela Universidade Federal do Rio de Janeiro - UFRJ \\ lacardoso2002@yahoo.com.br \\ Celso Funcia Lemme \\ Doutor em Administração pela Universidade Federal do Rio de Janeiro - UFRJ \\ Professor da Universidade Federal do Rio de Janeiro - UFRJ \\ celso@ coppead.ufrj.br
}

\section{RESUMO}

Examinando as informações divulgadas pelas empresas líderes na publicação de relatórios de sustentabilidade no Brasil, esta pesquisa buscou verificar a existência de uma justificativa empresarial (business case) para suas ações ambientais. Com o estabelecimento de clara associação entre desempenho ambiental e financeiro, as ações ambientais teriam conexão consistente com a estratégia corporativa, influenciando o processo de tomada de decisão empresarial e reduzindo os riscos de redução ou abandono em momentos de dificuldade econômica ou escassez de tempo dos gestores. Em linha com pesquisas anteriores, os resultados indicaram que as empresas, de diversos setores, ainda pouco fazem esta associação, tanto nos relatórios de sustentabilidade quanto nos websites. Para se tornarem mais efetivos como instrumentos de gestão e comunicação, os relatórios de sustentabilidade poderiam reduzir o número de páginas, destacar os vínculos com a estratégia empresarial e a gestão operacional e apresentar uma justificativa empresarial para as práticas ambientais. O aperfeiçoamento na divulgação das informações ambientais, relacionando-as com o desempenho financeiro, tornaria mais simples para os diversos stakeholders a tarefa de diferenciar e recompensar as empresas que adotam uma gestão consistentemente voltada para a sustentabilidade.

Palavras-chave: Desempenho financeiro; Iniciativas ambientais; Relatórios de sustentabilidade; Sustentabilidade Corporativa.

\section{IN SEARCH OF A BUSINESS CASE FOR THE ENVIRONMENTAL INITIATIVES OF LEADING BRAZILIAN COMPANIES IN SUSTAINABILITY REPORTING}

\begin{abstract}
Examining the information disclosed in the publications of the leading companies in sustainability reporting in Brazil, this study aimed to verify the existence of a business case for these companies' environmental actions. The identification of a clear link between environmental initiatives and corporate financial performance can help to place environmentally friendly practices as a key part of corporate strategy, reducing the risk that these practices could be scaled back or even discarded by future decision makers in times of economic or managerial distress. Supporting previous studies, the research results indicate that enterprises in different sectors still do not make the link between financial advantage and environmentally friendly practices, either in sustainability reports or on their websites. Sustainability reports could shorten, focusing on business strategy and relevant economic issues, showing a clear business case for environmental practices. The results also stress the need for improvement in the dissemination of environmental information, indicating its potential as a tool investors might use to identify and reward companies that focus on sustainability. Keywords: Corporate Sustainability; Environmental Initiatives; Financial Performance; Sustainability Reports.
\end{abstract}




\section{INTRODUÇÃO}

$\mathrm{O}$ dilema entre as iniciativas que visam a proteger o meio ambiente no longo prazo e as ações que proporcionam apenas resultados financeiros no curto prazo vem sendo discutido com intensidade crescente. Retratando a atenção atribuída aos fatores ambientais, em um estudo feito em 2003 a UNEP FI (United Nations Environment Programme Finance Initiative) verificou que algumas empresas já estavam levando em consideração o bem-estar da sociedade e do meio ambiente em seus esforços de crescimento econômico.

O grau de associação entre as ações ambientais e o desempenho financeiro corporativo tornou-se um importante campo de estudo, uma vez que vincular estas questões significa encontrar uma justificativa de negócios (business case) para as práticas de sustentabilidade das empresas. Como consequência, este processo permite que a adoção de ações ambientais passe a ser defendida em termos financeiros e não apenas com argumentos de caráter qualitativo.

Este ponto de vista foi abordado em estudo da consultoria A. T. Kearney (Mabler et al, 2009), que analisou 99 empresas presentes no Dow Jones Sustainability Index (DJSI) ou no Goldman Sachs SUSTAIN, observando que tiveram um diferencial de desempenho de $10 \%$ e $15 \%$ nos respectivos períodos, em relação à média do mercado. O estudo concluiu que somente as empresas estrategicamente sustentáveis poderão emergir mais fortes de crises financeiras, uma vez que serão reconhecidas por investidores que sabem identificar o valor de longo prazo da sustentabilidade.

No Brasil, a consultoria Deloitte (2009) realizou pesquisa no período de março a abril de 2009, por meio de questionário respondido por 115 empresas que atuam no país e detectou-se que $69 \%$ informaram que o cenário econômico não impactou seus investimentos sustentáveis; $78 \%$ indicaram adotar práticas de sustentabilidade e que estas já estão se refletindo em todas as etapas da cadeia produtiva, por meio de mudanças no seu portfólio de produtos ou processos de produção, com $40 \%$ das empresas da amostra já tendo feito alterações desta natureza.

Esta pesquisa, realizada, em sua maior parte, no primeiro semestre de 2009, teve como objetivo identificar o grau de associação entre as ações ambientais e o desempenho financeiro nas informações públicas das empresas líderes encontradas na publicação de relatórios de sustentabilidade no Brasil, e que tem como objetivo a tentativa de encontrar uma justificativa de negócios (business case) para as práticas ambientais. Como consequência desta identificação, as iniciativas ambientais seriam justificadas com argumentos de caráter quantitativo e monetário, tornando-as mais resistentes a alterações na gestão da empresa e nas mudanças na escala de prioridades em momentos de dificuldade financeira.

O restante deste artigo está organizado em quatro itens: o segundo, faz uma breve revisão de literatura; o terceiro, apresenta a metodologia utilizada na pesquisa; o quarto, aborda os resultados; e, finalmente, o quinto, resume as considerações finais.

\section{REVISÃO DA LITERATURA}

Apontando a existência de uma relação positiva entre desempenho ambiental e financeiro, o estudo de Klassen e McLaughlin (1996), que teve como referência o período de 1985 a 1991, verificou que, quando se tornavam públicas as práticas ambientais que alteravam positivamente os ganhos de mercado da empresa ou diminuíam seus custos, os investidores mudavam suas perspectivas e percepções de valor das empresas, verificando-se retornos anormais positivos das ações.

Feldman, Ameer e Soyka (1996), que analisaram 330 empresas pertencentes ao S\&P 500 no período de 1988 a 1994, concluíram que a adoção de melhores práticas ambientais reduziu significativamente seu risco sistêmico e que esta alteração reduziu o custo de capital em até $5 \%$.

Revista de Gestão Social e Ambiental - RGSA, São Paulo, v. 5, n. 2, p. 63-78, mai./ago. 2011. 
Cohen, Fenn e Konar (1997) analisaram todas as empresas pertencentes ao S\&P 500 no período de 1987 a 1991 e seus resultados indicaram que a carteira formada por empresas com alto desempenho ambiental teve desempenho financeiro em patamar igual ou superior ao das demais.

Arx e Ziegler (2008) analisaram o período de 2003 a 2006 e concluíram que, nos Estados Unidos e Europa, empresas com atividades sociais e ambientais eram mais valorizadas pelos mercados em comparação com outras do mesmo setor, embora os efeitos positivos sobre a média mensal do retorno da ação no período fossem não-lineares, parecendo ser mais robustos nos Estados Unidos do que na Europa.

Outros estudos não apontaram para esta relação com tanto otimismo, como o trabalho de Kreander et al (2000), que compararam o desempenho de 40 fundos de ações que investiam somente em empresas consideradas ambiental e socialmente responsáveis com o de 40 fundos que não apresentavam esta preocupação, todos localizados em países como Alemanha, Bélgica, Holanda, Inglaterra, Noruega, Suécia e Suíça, entre 1996 e 1998. Esse estudo não apontou diferenças estatisticamente significativas entre os desempenhos, embora os que tinham a preocupação de investir em empresas responsáveis tenham apresentado menor desvio-padrão na distribuição dos retornos.

Divergências também podem ser percebidas com os resultados do estudo de Jacobs, Singhal e Subramanian (2009), que visou a verificar os efeitos do desempenho ambiental no valor de mercado das empresas, pela reação observada no mercado de capitais diante da publicação de 811 anúncios na imprensa de informações ambientais, no período de 2004 a 2006 . O trabalho não identificou reação significativa ao conjunto de informações, embora tenha encontrado reações estatisticamente significativas para algumas subcategorias de informações, como os anúncios de doações filantrópicas para causas ambientais, reduções voluntárias de emissões e certificação da ISO 14001.

Já o estudo de Santaló e Kock (2006), que utilizou a base de dados da Agência de Proteção Ambiental Americana (United States Environmental Protection Agency) referente ao período de 1996 a 2003, relatou que empresas reconhecidas como baixas poluidoras apresentaram substanciais retornos anormais positivos nos sete anos seguintes à publicação das informações ambientais, em torno de 14 a $17 \%$ ao ano, enquanto as grandes poluidoras não apresentavam retornos anormais, positivos ou negativos.

Cavalcante, Bruni e Costa (2009) confrontaram o desempenho de uma carteira teórica formada pelas ações que compõem o Índice de Sustentabilidade Empresarial (ISE) da BM\&FBOVESPA com o das carteiras teóricas que formam o Índice Bovespa (Ibovespa) e o Índice Brasil (IBrX), retroagindo o ISE para período anterior à sua criação, por meio de uma carteira de referência. Esse estudo não encontrou evidências de desempenho superior do ISE no período posterior à sua criação, apontando que o índice revelou-se mais volátil do que os dois outros índices no período considerado, havendo, porém, indicações de que as carteiras retroagidas do ISE apresentavam melhor desempenho e que a precificação teria ocorrido antes de sua divulgação oficial.

Em resumo, parece não haver resultados conclusivos nos estudos acadêmicos realizados na tentativa de relacionar desempenho ambiental com o financeiro. De acordo com Salzmann, Steger e Ionescu-Somers (2005), a dificuldade em mensurar os efeitos das iniciativas sustentáveis no desempenho financeiro corporativo está atrelada, entre outros fatos: 1) a existência de um tempo razoável entre a prática sustentável e seu efeito, que pode ocasionar frustração e consequente ajuste nas atividades corporativas, como a suspensão de iniciativas, independentemente de seus potenciais efeitos positivos futuros; e 2) ao problema da mensuração do desempenho ambiental e financeiro exigir julgamento, o que possibilita o uso de diferentes métodos.

Sobre a não-ocorrência de resultados conclusivos em todas as categorias de estudos do relacionamento entre práticas ambientais e desempenho financeiro, Brito (2005) acredita que existem razões teóricas e empíricas capazes de justificar estas contradições. Entre elas, está o fato

Revista de Gestão Social e Ambiental - RGSA, São Paulo, v. 5, n. 2, p. 63-78, mai./ago. 2011. 
de as empresas com melhor desempenho financeiro possuírem mais recursos disponíveis para as práticas ambientais, gerando uma causalidade reversa que pode dificultar a interpretação dos resultados estatísticos. Além disto, a falta de indicadores objetivos de desempenho ambiental, consolidados e aplicáveis aos diferentes setores de atividade econômica, pode criar vieses nos estudos empíricos e influenciar, de forma significativa, os resultados encontrados, fazendo com que estudos adicionais neste campo ainda sejam necessários até que a teoria esteja efetivamente consolidada.

Segundo a United Nations Conference on Trade and Development (2000 apud Nossa, 2002), stakeholders que são financeiramente sofisticados esperam ver a ligação entre desempenho ambiental e financeiro nos relatórios ambientais, uma vez que uma empresa que reconhece suas responsabilidades ambientais, institui sistemas efetivos e apropriados de gerenciamento ambiental e adota tecnologias ambientalmente amigáveis que minimizarão sua exposição ao risco decorrente de incidentes ambientais.

Reafirmando este argumento, Carpentier, Patterson e Malthouse (2003) identificaram uma pressão por parte dos stakeholders por uma clara divulgação de informações a respeito das práticas ambientais corporativas, mas colocaram em dúvida a qualidade das informações divulgadas. Como consequência da forma inadequada de divulgação, esse estudo apontou que os stakeholders, sem um conhecimento de todas as informações relevantes, não conseguem visualizar, de forma objetiva, o impacto das ações ambientais no desempenho financeiro da empresa e, com isso, podem acabar abandonando a análise das ações sustentáveis.

Reppeto e Austin (2000), em estudo sobre a integração de questões ambientais com o sucesso na análise financeira, verificaram que as informações sobre as práticas ambientais divulgadas pelas empresas não forneciam dados suficientes aos investidores para que pudessem tomar decisões. Isto reforça a necessidade das empresas apresentarem suas informações ambientais associadas às justificativas de negócios.

Epstein e Roy (2003) realizaram um estudo com o objetivo de identificar a justificativa de negócios em ações sustentáveis das empresas, pela análise de relatórios corporativos de sustentabilidade divulgados por 20 empresas. Os autores classificaram as informações socioambientais divulgadas de acordo com uma escala de quatro níveis. A composição dos níveis variava desde a apresentação de informações apenas descritivas (nível 1), passando por informações quantitativas físicas ou operacionais (nível 2), chegando a informações quantitativas e monetárias referentes aos investimentos, custos e despesas incorridas nas práticas socioambientais (nível 3) e, no último nível, aos benefícios financeiros provenientes das práticas (nível 4). Os autores concluíram que a maioria das empresas, embora em processo de conscientização sobre a questão, ainda não havia adotado práticas adequadas para avaliar os impactos das iniciativas de desenvolvimento sustentável sobre o desempenho financeiro, constatando que os relatórios de sustentabilidade de poucas empresas continham, efetivamente, a requisitada justificativa de negócios para suas ações sustentáveis de caráter social e ambiental.

Neste sentido, Hess (2003) analisou a presença da justificativa de negócios (business case) para práticas sustentáveis em 62 entrevistas com representantes de instituições financeiras europeias e norte-americanas. Nelas, verificou-se que a não exploração da justificativa de negócios se deu pelo fato dos riscos sociais e ambientais serem, muitas vezes, analisados separadamente dos riscos financeiros, talvez pela ausência de conhecimento e instrumentos adequados para definir os riscos provenientes das práticas sustentáveis.

Já Yachin et al (2006) ressaltaram um interesse crescente de corporações, governos, organizações não-governamentais e analistas financeiros nas associações entre as práticas de sustentabilidade e desempenho financeiro e que, para identificar esta associação, o efeito das ações sustentáveis deveria ser isolado das outras variáveis e expresso em termos quantitativos e

Revista de Gestão Social e Ambiental - RGSA, São Paulo, v. 5, n. 2, p. 63-78, mai./ago. 2011. 
financeiros. Esse estudo sugeriu ser possível traduzir o impacto das práticas sustentáveis em avaliação financeira, utilizando métricas de análise financeira tradicionais.

Levando-se em consideração que o reconhecimento da divulgação das práticas sustentáveis é crucial para a condução das melhorias no desempenho da sustentabilidade, cabe citar o relatório da Ceres-ACCA (2007), publicado anualmente com o intuito de reconhecer e incentivar a elaboração de relatórios sobre sustentabilidade em empresas dos Estados Unidos, Canadá e México. Segundo a publicação, esses relatórios devem fornecer mais detalhes sobre a integração de práticas sustentáveis com resultados financeiros, ou seja, a justificativa de negócios não foi verificada de maneira clara pelos pesquisadores.

Outro estudo interessante foi realizado por Knox, Maklan e French (2005), por meio da análise das 150 empresas melhor posicionadas no índice FTSE4Good, testando a hipótese de que a responsabilidade social corporativa não é frequentemente associada ao desempenho financeiro. Essa pesquisa encontrou evidência de relação positiva entre o tamanho da empresa e a associação das práticas de sustentabilidade com o desempenho financeiro corporativo.

Como foco no setor bancário, o estudo de Wajnberg e Lemme (2009) analisou informações públicas sobre as práticas de sustentabilidade divulgadas por 45 instituições financeiras brasileiras, na tentativa de verificar a presença de uma justificativa de negócios em um setor extremamente orientado para resultados. Essa pesquisa revelou que a divulgação de informações pelo setor bancário brasileiro não permite relacionar suas práticas de sustentabilidade com o desempenho financeiro corporativo e que as práticas de sustentabilidade e os maiores níveis de relacionamento com o desempenho financeiro são mais presentes na divulgação de informações dos maiores bancos.

Reafirmando a necessidade de divulgação adequada das práticas corporativas que visam à sustentabilidade, Gasparino e Ribeiro (2007) relatam que, principalmente, grandes empresas de capital aberto e que têm ações na Bolsa de Valores de Nova Iorque já atribuem importância à divulgação de suas preocupações com o meio ambiente, uma vez que esta atitude pode proporcionar credibilidade e confiabilidade perante os usuários da informação, refletindo-se na capacidade competitiva.

Em relação à tentativa de aprimorar a elaboração de relatórios de sustentabilidade, cabe ressaltar a iniciativa da Global Reporting Initiative (GRI), modelo de elaboração de relatórios de sustentabilidade lançado pela organização não-governamental americana Coalition for Environmentally Responsible Economies (CERES) e pelo United Nations Environment Programme em 1997, com o objetivo de ajudar as empresas no entendimento e na divulgação de suas ações sustentáveis, melhorando a qualidade e a utilidade dos relatórios de sustentabilidade (Delai e Takahashi, 2008).

Em pesquisa efetuada por Figge et al (2006), onde foi analisado o desempenho ambiental de 65 empresas europeias do setor manufatureiro, concluiu-se que as informações corporativas publicadas em relatórios ambientais carecem de melhorias, tanto no que diz respeito à qualidade da informação divulgada, como quanto à forma de comunicação e à necessidade de padronização dos relatórios corporativos. Além disto, esse estudo ressaltou a importância da tradução das práticas corporativas relacionadas ao desempenho ambiental em uma linguagem de investidores e gestores.

O crescente reconhecimento da importância dos relatórios de sustentabilidade se manifesta na sua produção intensa, refletida no fato de que são publicados por ano mais de 2.500 relatórios no mundo. Embora o número tenha se mantido estável na Europa, Oceania e América do Norte, vem aumentando significativamente nos países em desenvolvimento (A Global Reporters Research Publication, 2008). Torna-se, portanto, relevante a discussão acerca das características desses relatórios e de suas possíveis melhorias.

Revista de Gestão Social e Ambiental - RGSA, São Paulo, v. 5, n. 2, p. 63-78, mai./ago. 2011. 


\section{MÉTODO DE PESQUISA}

Partindo do princípio de que um conjunto formado por empresas de grande destaque em publicações de relatórios de sustentabilidade, ou que possuem relevante interesse neste tema, apresentaria maior probabilidade de identificação de uma justificativa de negócios para suas práticas ambientais, este trabalho utilizou como base para a seleção de sua amostra a publicação The road to credibility: a survey of sustainability reporting in Brazil (A global reporters research publication, 2008) elaborado pela consultoria internacional Sustainability e pela Fundação Brasileira para o Desenvolvimento Sustentável (FBDS), em parceria com o United Nations Environment Program, publicado em 2008.

A pesquisa, que utilizou metodologia de pontuação padronizada da SustainAbility para ordenar os relatórios de sustentabilidade no Brasil, visou analisar a qualidade desses relatórios, incentivar as empresas brasileiras a aprimorarem suas práticas de informações e destacar o que empresas globais podem aprender com as brasileiras. Com relação à metodologia utilizada para seleção da amostra, foram seguidos três passos, descritos detalhadamente na publicação, que podem ser resumidos da seguinte forma:

$1^{\circ}$ passo: Identificar empresas com grande propensão a publicar relatórios de sustentabilidade, pela verificação de dez requisitos associados a aspectos como porte das empresas, liquidez em bolsa de valores, premiação associada à gestão para sustentabilidade e presença em índices, rankings e banco de dados voltados para sustentabilidade. O resultado foi um universo de 275 empresas;

$2^{\circ}$ passo: Criação de uma "long list", eliminando-se as empresas que não atendiam, pelo menos, dois dos dez requisitos ou que não haviam publicado relatório de sustentabilidade nos últimos dois anos; restaram 76 empresas, cabendo destacar que se considerou como relatório de sustentabilidade todo aquele que cobrisse aspectos ambientais, sociais, econômicos e de governança corporativa;

$3^{\circ}$ passo: Criação de uma "short list", com 28 empresas, a partir da utilização de nove critérios básicos de avaliação de relatórios de sustentabilidade, segundo a metodologia do programa Global Reporters.

Entre os patrocinadores da publicação, Banco Itaú, Light, Natura e Sabesp estavam presentes na short list. Em relação aos demais, o relatório da Rhodia Energy Services não se encontrava disponível no site na época de seleção da amostra e o SESI, Serviço Social da Indústria, não é uma empresa propriamente dita. Assim, foram incluídos na amostra dessa pesquisa os demais patrocinadores, ou seja, as empresas Shell Brasil, Holcim Brasil e Tetra Pak, pelo envolvimento relevante com a questão da sustentabilidade, totalizando 31 empresas, conforme apresentado, em ordem alfabética, na Tabela 1. 
Tabela 1: Empresas componentes da amostra

\begin{tabular}{|c|c|c|c|}
\hline 1. & AES Eletropaulo & 12. Coelce & 23. Samarco Mineração \\
\hline 2. & AmBev & 13. Copagaz & 24. Serasa \\
\hline 3. & Ampla & 14. Copel & 25. Shell Brasil \\
\hline 4. & Aracruz & 15. Energias do Brasil & 26. Souza Cruz \\
\hline 5. & Banco Itaú & 16. Holcim Brasil & 27. Suzano Petroquímica \\
\hline 6. & Banco Real & 17. Light & 28. Tetra Pak \\
\hline 7. & Bradesco & 18. Natura & 29. Usiminas \\
\hline 8. & Bunge & 19. Petrobras & 30. VCP \\
\hline 9. & Celulose Irani & 20. Philips do Brasil & 31. Veracel Celulose \\
\hline & Cemig & 21. Roche Brasil & \\
\hline & Coelba & 22. Sabesp & \\
\hline
\end{tabular}

Fonte: Elaborado pelos autores

As fontes de dados foram os últimos relatórios de sustentabilidade ou equivalentes divulgados pelas empresas, bem como seus websites, esses últimos nas áreas que indicavam associação com ações ambientais e relações com investidores. As empresas foram classificadas de acordo com seus setores econômicos, subsetores ou segmentos, segundo critério da BM\&FBOVESPA, como pode ser visto na Tabela 2.

Tabela 2: Divisão setorial das empresas componentes da amostra

\begin{tabular}{|c|c|c|}
\hline Setor & Subsetor / Segmento & Empresa \\
\hline \multirow{3}{*}{ Utilidade Pública } & Energia Elétrica & $\begin{array}{l}\text { AES Eletropaulo, Ampla, Cemig, Coelba, } \\
\text { Coelce, Copel, Energias do Brasil e Light }\end{array}$ \\
\hline & Gás & Copagaz \\
\hline & Água e Saneamento & Sabesp \\
\hline \multirow{5}{*}{ Materiais Básicos } & Papel e Celulose & $\begin{array}{l}\text { Aracruz, Celulose Irani, VCP } \\
\text { e Veracel Celulose }\end{array}$ \\
\hline & Mineração & Samarco Mineração \\
\hline & Petroquímicos & Suzano Petroquímica \\
\hline & Embalagens & Tetra Pak \\
\hline & Siderurgia & Usiminas \\
\hline \multirow{5}{*}{$\begin{array}{l}\text { Consumo Não } \\
\text { Cíclico }\end{array}$} & Bebidas & AmBev \\
\hline & Produtos de Uso Pessoal & Natura \\
\hline & Medicamentos & Roche Brasil \\
\hline & Fumo & Souza Cruz \\
\hline & Alimentos & Bunge \\
\hline \multirow{2}{*}{ Financeiro } & Intermediários Financeiros & Banco Itaú, Banco Real e Bradesco \\
\hline & Serviços Financeiros Diversos & Serasa \\
\hline $\begin{array}{l}\text { Petróleo, Gás e } \\
\text { Biocombustíveis }\end{array}$ & Petróleo, Gás e Biocombustíveis & Petrobras e Shell Brasil \\
\hline Construção & Materiais de Construção & Holcim Brasil \\
\hline Consumo Cíclico & Utilidades & Philips do Brasil \\
\hline
\end{tabular}

Fonte: Elaborado pelos autores 
Foi utilizado nesse estudo, com algumas adaptações, a metodologia do estudo de Epstein e Roy (2003), discutido na revisão de literatura, que classifica as informações socioambientais de acordo com uma escala de níveis de 1 a 4 . As informações são classificadas no primeiro nível quando forem qualitativas, de caráter apenas descritivo; no segundo nível, quando forem quantitativas, mas expressas em números físicos ou operacionais, não atreladas diretamente ao desempenho financeiro. Já nos dois últimos níveis, as informações de caráter socioambiental são quantitativas e monetárias, associadas, parcial ou integralmente, ao desempenho financeiro. No terceiro nível, são referentes aos investimentos, custos e despesas incorridas nas práticas socioambientais, sendo, então, parcialmente atreladas ao desempenho financeiro. No quarto e último nível, são relacionadas aos benefícios decorrentes dos investimentos, custos e despesas incorridos em tais práticas, estando, assim, completamente associadas ao desempenho financeiro.

Como este trabalho teve por objetivo avaliar o grau da associação das ações ambientais com o desempenho financeiro, a adaptação da metodologia se deu em dois sentidos: primeiro, tratou apenas das informações de caráter ambiental, excluindo as de caráter social; segundo, o nível 1 da metodologia original, que registra informações de caráter apenas descritivo, foi desconsiderado.

Em resumo, as informações de caráter ambiental presentes nos relatórios de sustentabilidade e nos websites das empresas foram classificadas em três níveis, definidos a seguir:

- Nível 1: Informações quantitativas apenas de natureza física ou operacional, portanto, não diretamente relacionadas ao desempenho financeiro corporativo;

- Nível 2: Informações monetizadas referentes a investimentos, custos e despesas, portanto, parcialmente associadas ao desempenho financeiro corporativo, pois não indicam os benefícios gerados;

- Nível 3: Informações monetizadas referente a benefícios, portanto, diretamente associadas ao desempenho financeiro corporativo.

Informações que tratavam da mesma prática ambiental e estavam presentes em diversos momentos ao longo do relatório de sustentabilidade ou do website foram consideradas apenas uma vez na contagem de informações.

Como procedimento adicional, foi feita uma classificação das empresas pelo grau de associação entre as práticas ambientais e o desempenho financeiro, utilizando-se uma pontuação calculada pelo número de vezes que informações de um dado nível apareceram, multiplicado pelo peso do respectivo nível. Em um primeiro momento, foi atribuído peso 1 a todos os níveis, ou seja, se no relatório de sustentabilidade e no website verificaram-se 10 informações categorizadas como de nível 1; 14, de nível 2 e 1 de nível 3, a empresa teria 25 pontos. Em um segundo passo, foi considerado como peso de cada nível sua própria classificação, ou seja, peso 1 para as informações pertencentes ao nível 1, peso 2 para as de nível 2 e peso 3 para as pertencentes ao nível 3 . Assim, utilizando o exemplo anterior, a referida empresa teria 41 pontos $(1 \times 10+2 \times 14+1 \times 3=41)$.

\section{RESULTADOS}

Inicialmente, chamou a atenção o porte dos relatórios de sustentabilidade das 31 empresas da amostra. A Tabela 3 resume o número de páginas dos relatórios analisados. 
Tabela 3: Classificação dos relatórios analisados pelo número de páginas

\begin{tabular}{|c|c|c|}
\hline Intervalos & Quantidade de Relatórios & Participação \\
\hline 0 - 100 páginas & 8 & $25,81 \%$ \\
\hline 100 - 200 páginas & 21 & $67,74 \%$ \\
\hline 200 - 300 páginas & 2 & $6,45 \%$ \\
\hline Total & 31 & $100 \%$ \\
\hline
\end{tabular}

Fonte: Elaborado pelos autores

A média foi de 128 páginas, sendo o menor relatório o da Holcim Brasil, com 34 páginas, e o maior o da Serasa, com 263 páginas. Apenas dois relatórios de sustentabilidade tinham menos do que 50 páginas e a maior parte apresentava entre 100 e 200 páginas. Esses resultados levantam dúvida sobre a existência de público efetivamente disposto a ler relatórios de tão grande porte. A Tabela 4 apresenta as médias de páginas dos sete setores econômicos e dos subsetores presentes na amostra.

Tabela 4: Média de páginas dos relatórios analisados, por setor de atividade

\begin{tabular}{|c|c|c|c|}
\hline Setor & Subsetor / Segmento & Média de Páginas & Média do Setor \\
\hline \multirow{3}{*}{ Utilidade Pública } & Energia Elétrica & 154 & \multirow{3}{*}{152} \\
\hline & Gás & 114 & \\
\hline & Água e Saneamento & 175 & \\
\hline \multirow{5}{*}{ Materiais Básicos } & Papel e Celulose & 111 & \multirow{5}{*}{134} \\
\hline & Mineração & 157 & \\
\hline & Petroquímicos & 155 & \\
\hline & Embalagens & 129 & \\
\hline & Siderurgia & 188 & \\
\hline \multirow{5}{*}{$\begin{array}{c}\text { Consumo Não } \\
\text { Cíclico }\end{array}$} & Bebidas & 115 & \multirow{5}{*}{90} \\
\hline & Produtos de Uso Pessoal & 94 & \\
\hline & Medicamentos & 89 & \\
\hline & Fumo & 80 & \\
\hline & Alimentos & 73 & \\
\hline \multirow{2}{*}{ Financeiro } & Intermediários Financeiros & 120 & \multirow{2}{*}{156} \\
\hline & Serviços Financeiros Diversos & 263 & \\
\hline $\begin{array}{l}\text { Petróleo, Gás e } \\
\text { Biocombustiveis }\end{array}$ & Petróleo, Gás e Biocombustiveis & 84 & 84 \\
\hline Construção & Materiais de Construção & 34 & 34 \\
\hline Consumo Cíclico & Utilidades & 110 & 110 \\
\hline
\end{tabular}

Fonte: Elaborado pelos autores

Relatórios com grande número de páginas, de utilidade duvidosa para os leitores, não parecem ser característica de setores específicos. O setor de construção, com número de páginas bem inferior, foi representado apenas pela empresa Holcim Brasil, não sendo possível generalizar a observação.

Quanto à segunda fonte de dados da pesquisa, as áreas dos websites, observou-se que, em geral, não traziam informações adicionais aos relatórios de sustentabilidade. Apenas 7 websites, dos 31 analisados, apresentaram informações de caráter ambiental que pudessem ser classificadas em 
um dos três níveis utilizados nesta pesquisa e que não constavam nos respectivos relatórios de sustentabilidade.

Após uma visão do porte dos relatórios de sustentabilidade e dos websites, a Tabela 5 consolida os níveis de divulgação de informações ambientais, delineando o perfil do relacionamento entre desempenho ambiental e financeiro nas empresas selecionadas.

Tabela 5: Quantidade e frequência relativa das informações, por nível de divulgação

\begin{tabular}{|ccc|}
\hline Nível & Quantidade & Participação \\
\hline 1 & 229 & $59,02 \%$ \\
\hline 2 & 139 & $35,82 \%$ \\
\hline 3 & 20 & $5,15 \%$ \\
\hline Total & 388 & $100,00 \%$ \\
\hline
\end{tabular}

Fonte: Elaborado pelos autores

Apenas 5\% de todas as informações de caráter ambiental eram monetizadas e relacionadas aos benefícios decorrentes das ações ambientais, diretamente associadas ao desempenho financeiro corporativo. Adicionalmente, apenas $36 \%$ das informações ambientais eram relacionadas aos investimentos, custos e despesas incorridas em ações ambientais e, portanto, estavam parcialmente associadas ao desempenho financeiro corporativo. Predominaram informações de nível 1, em que as ações ambientais são expressas em números de natureza física ou operacional, sem associação com o desempenho financeiro corporativo. Assim, a justificativa de negócios (business case) das iniciativas ambientais não fica clara. A análise setorial desta composição encontra-se na Tabela 6.

Tabela 6: Divisão por setor e subsetor/segmento da quantidade e frequência relativa das informações, por nível de divulgação

\begin{tabular}{|c|c|c|c|c|c|}
\hline Setor & Subsetor / Segmento & $\begin{array}{l}\text { Quantidade de } \\
\text { Informações }\end{array}$ & \% Nível 1 & \% Nível 2 & \% Nível 3 \\
\hline \multirow{4}{*}{ Utilidade Pública } & Energia Elétrica & 135 & $48,9 \%$ & $46,7 \%$ & $4,4 \%$ \\
\hline & Gás & 6 & $83,3 \%$ & $16,7 \%$ & $0,0 \%$ \\
\hline & Água e Saneamento & 10 & $60,0 \%$ & $30,0 \%$ & $10,0 \%$ \\
\hline & Setor & 151 & $51,0 \%$ & $44,4 \%$ & $4,6 \%$ \\
\hline \multirow{6}{*}{ Materiais Básicos } & Papel e Celulose & 51 & $64,7 \%$ & $31,4 \%$ & $3,9 \%$ \\
\hline & Mineração & 11 & $63,6 \%$ & $27,3 \%$ & $9,1 \%$ \\
\hline & Petroquímicos & 13 & $53,8 \%$ & $46,2 \%$ & $0,0 \%$ \\
\hline & Embalagens & 8 & $87,5 \%$ & $0,0 \%$ & $12,5 \%$ \\
\hline & Siderurgia & 12 & $58,3 \%$ & $33,3 \%$ & $8,3 \%$ \\
\hline & Setor & 95 & $64,2 \%$ & $30,5 \%$ & $5,3 \%$ \\
\hline \multirow{6}{*}{$\begin{array}{c}\text { Consumo Não } \\
\text { Cíclico }\end{array}$} & Bebidas & 9 & $66,7 \%$ & $22,2 \%$ & $11,1 \%$ \\
\hline & Produtos de Uso Pessoal & 9 & $77,8 \%$ & $22,2 \%$ & $0,0 \%$ \\
\hline & Medicamentos & 8 & $50,0 \%$ & $25,0 \%$ & $25,0 \%$ \\
\hline & Fumo & 13 & $69,2 \%$ & $30,8 \%$ & $0,0 \%$ \\
\hline & Alimentos & 11 & $63,6 \%$ & $27,3 \%$ & $9,1 \%$ \\
\hline & Setor & 50 & $66,0 \%$ & $26,0 \%$ & $8,0 \%$ \\
\hline \multirow{3}{*}{ Financeiro } & Intermediários Financeiros & 33 & $57,6 \%$ & $33,3 \%$ & $9,1 \%$ \\
\hline & Serviços Financeiros Diversos & 9 & $77,8 \%$ & $22,2 \%$ & $0,0 \%$ \\
\hline & Setor & 42 & $61,9 \%$ & $31,0 \%$ & $7,1 \%$ \\
\hline $\begin{array}{l}\text { Petróleo, Gás e } \\
\text { Biocombustíveis }\end{array}$ & Petróleo, Gás e Biocombustíveis & 27 & $63,0 \%$ & $37,0 \%$ & $0,0 \%$ \\
\hline Construção & Materiais de Construção & 13 & $61,5 \%$ & $38,5 \%$ & $0,0 \%$ \\
\hline Consumo Cíclico & Utilidades & 10 & $70,0 \%$ & $20,0 \%$ & $10,0 \%$ \\
\hline
\end{tabular}

Fonte: Elaborado pelos autores 
Os resultados apontam a maior incidência de informações de nível 1 em todos os setores, subsetores ou segmentos de atuação. Cabe, entretanto, destacar o subsetor de energia elétrica, que apresenta certo equilíbrio entre as participações dos dois primeiros níveis de divulgação. A Tabela 7 relaciona, de forma resumida, as poucas práticas divulgadas pelas empresas que foram classificadas como de nível 3.

Tabela 7: Práticas de nível 3 divulgadas pelas empresas da amostra

\begin{tabular}{|l|l|l|}
\hline \multicolumn{1}{|c|}{ Empresa } & Nível 3 & \multicolumn{1}{c|}{ Práticas com Indicações de Valor } \\
\hline Ampla & 2 & $\begin{array}{l}\text { Adoção de Medidas de Redução do Consumo de Energia } \\
\text { Adoção do Carro Elétrico }\end{array}$ \\
\hline Banco Real & 2 & $\begin{array}{l}\text { Comercialização de Créditos de Carbono } \\
\text { Venda de Lixo Reciclável }\end{array}$ \\
\hline Energias do Brasil & 2 & $\begin{array}{l}\text { Adoção de Medidas de Redução do Consumo de Energia } \\
\text { Reciclagem de Resíduos }\end{array}$ \\
\hline Roche Brasil & 2 & $\begin{array}{l}\text { Utilização nas Caldeiras apenas de Gás Natural e Tratamento da Água } \\
\text { Reciclagem de Resíduos }\end{array}$ \\
\hline AmBev & 1 & Reaproveitamento de Resíduos Industriais \\
\hline Aracruz & 1 & Adoção de Sistema de Previsão e Aviso para Controle de Doenças Foliares \\
\hline Bradesco & 1 & Adoção de Medidas de Redução do Consumo de Energia \\
\hline Bunge & 1 & Utilização de Biomassa e Redução dos Custos com Combustíveis \\
\hline Celulose Irani & 1 & Venda de Créditos de Carbono \\
\hline Coelba & 1 & Comercialização de Resíduos \\
\hline Coelce & 1 & Reciclagem de Resíduos \\
\hline Philips do Brasil & 1 & Adoção de Medidas de Redução do Consumo de Energia \\
\hline Sabesp & 1 & Adoção de Medidas de Redução do Consumo de Energia \\
\hline Samarco Mineração & 1 & Incentivo a Reutilização de Peças \\
\hline Tetra Pak & 1 & Reciclagem de Resíduos \\
\hline Usiminas & 1 & Comercialização de Resíduos \\
\hline Informações Nível 3 & 20 & \\
\hline
\end{tabular}

Fonte: Elaborado pelos autores

As ações ambientais associadas diretamente aos benefícios financeiros dizem respeito, em sua maior parte, à reciclagem ou comercialização de resíduos, práticas responsáveis por 9 das 20 informações de nível 3 encontradas e à adoção de medidas de redução do consumo de energia, citadas em 5 informações. Isto pode indicar que, nas questões ambientais, as empresas ainda estão mais voltadas para ecoeficiência ou atividades-meio do que para a definição de modelos de negócios (atividade-fim) realmente novos.

Uma classificação das empresas pelo grau de associação entre as práticas ambientais e o desempenho financeiro pode ser estabelecida pela pontuação atribuída a cada uma, obtida pelo número de vezes que informações de um dado nível apareceram, multiplicado pelo peso do nível. Em um primeiro momento, foi atribuído peso 1 a todos os níveis e, posteriormente, considerou-se o próprio número do nível (1, 2 ou 3) como peso.

Utilizando ponderação idêntica para todos os níveis de divulgação das informações ambientais, a pontuação máxima foi obtida pela empresa de energia elétrica Coelba, com 25 pontos. $\mathrm{Na}$ análise setorial, a maioria das empresas de energia elétrica ocupou posição relevante na associação entre ações ambientais e desempenho financeiro corporativo, destacando os três primeiros lugares para Coelba, Coelce e Energias do Brasil, seguidas da Ampla $\left(5^{\circ}\right), \operatorname{Copel}\left(7^{\circ}\right)$ e 
Light $\left(8^{\circ}\right)$. Banco Real $\left(4^{\circ}\right)$ e Petrobras $\left(6^{\circ}\right)$ completaram as dez primeiras posições, juntamente com duas representantes do setor de papel e celulose, Celulose Irani $\left(9^{\circ}\right)$ e Votorantim Celulose e Papel $\left(10^{\circ}\right)$.

Examinando-se a classificação com ponderação distinta entre os níveis de informação, as maiores pontuações continuaram no subsetor de energia elétrica, com Coelba, Coelce e Energias do Brasil, mantendo-se nas três primeiras posições, ainda acompanhadas de Ampla $\left(5^{\circ}\right)$, Light $\left(6^{\circ}\right)$ e Copel $\left(9^{\circ}\right)$. Mantiveram-se, também, nas dez posições iniciais, Banco Real $\left(4^{\circ}\right)$, Petrobras $\left(7^{\circ}\right)$, Celulose Irani $\left(8^{\circ}\right)$ e Votorantim Celulose e Papel $\left(10^{\circ}\right)$.

A presença das mesmas dez empresas nas duas classificações pode ser um indicador de efetiva liderança na associação entre ações ambientais e desempenho financeiro corporativo. Parece clara, também, a maior proximidade das empresas de energia elétrica com a definição de uma justificativa de negócios para as iniciativas ambientais.

Uma análise comparativa entre o número médio de páginas dos relatórios de sustentabilidade das empresas e a pontuação média atribuída às mesmas, utilizando ponderação semelhante ou distinta para os níveis de informação, pode propiciar melhor entendimento sobre possível relação entre o porte dos relatórios e os níveis de associação entre ações de caráter ambiental e desempenho financeiro corporativo. A Tabela 8 resume esta comparação.

Tabela 8: Divisão por setor e subsetor/segmento do número médio de páginas dos relatórios e da pontuação média da informação, com critério de pesos semelhantes e pesos distintos

\begin{tabular}{|c|c|c|c|c|}
\hline Setor & Subsetor / Segmento & $\begin{array}{l}\text { Número Médio } \\
\text { de Páginas }\end{array}$ & $\begin{array}{l}\text { Pontuação Média } \\
\text { Pesos Semelhantes }\end{array}$ & $\begin{array}{c}\text { Pontuação Média } \\
\text { Pesos Distintos }\end{array}$ \\
\hline \multirow{4}{*}{ Utilidade Pública } & Energia Elétrica & 154 & 16,9 & 26,3 \\
\hline & Gás & 114 & 6,0 & 7,0 \\
\hline & Água e Saneamento & 175 & 10,0 & 15,0 \\
\hline & Setor & 152 & 11,0 & 16,1 \\
\hline \multirow{6}{*}{ Materiais Básicos } & Papel e Celulose & 111 & 12,8 & 17,8 \\
\hline & Mineração & 157 & 11,0 & 16,0 \\
\hline & Petroquímicos & 155 & 13,0 & 19,0 \\
\hline & Embalagens & 129 & 8,0 & 10,0 \\
\hline & Siderurgia & 188 & 12,0 & 18,0 \\
\hline & Setor & 134 & 11,4 & 16,2 \\
\hline \multirow{6}{*}{ Consumo Não Cíclico } & Bebidas & 115 & 9,0 & 13,0 \\
\hline & Produtos de Uso Pessoal & 94 & 9,0 & 11,0 \\
\hline & Medicamentos & 89 & 8,0 & 14,0 \\
\hline & Fumo & 80 & 13,0 & 17,0 \\
\hline & Alimentos & 73 & 11,0 & 16,0 \\
\hline & Setor & 90 & 10,0 & 14,2 \\
\hline \multirow{3}{*}{ Financeiro } & Intermediários Financeiros & 120 & 11,0 & 16,7 \\
\hline & Serviços Financeiros Diversos & 263 & 9,0 & 11,0 \\
\hline & Setor & 156 & 10,0 & 13,8 \\
\hline Petróleo, Gás e Biocombustiveis & Petróleo, Gás e Biocombustíveis & 84 & 13,5 & 18,5 \\
\hline Construção & Materiais de Construção & 34 & 13,0 & 18,0 \\
\hline Consumo Cíclico & Utilidades & 110 & 10,0 & 14,0 \\
\hline
\end{tabular}

Fonte: Elaborado pelos autores

Os resultados sugerem a inexistência de relação entre o porte dos relatórios e a pontuação média, com pesos semelhantes ou distintos. Em outras palavras, a maior quantidade de páginas não se refletiu em melhor qualidade das informações. 


\section{CONSIDERAÇÕES FINAIS}

Esta pesquisa objetivou verificar a existência, nas informações públicas das empresas líderes em relatórios de sustentabilidade no Brasil, de uma justificativa de negócios (business case) para as suas ações ambientais, considerando que uma efetiva associação com o desempenho financeiro poderia embasar, de forma mais consistente, essas ações. Com o estabelecimento de um vínculo entre meio ambiente e valor, as ações ambientais passariam a ter sua importância considerada na estratégia corporativa e, por consequência, no processo de tomada de decisão dos gestores, evitando que em momentos de dificuldade econômica as empresas optassem por reduzi-las ou abandoná-las.

Os resultados indicaram que empresas de diversos setores pouco associam suas iniciativas ambientais com o desempenho financeiro nas informações divulgadas por meio de relatórios de sustentabilidade ou websites. Este relacionamento limitado entre ações ambientais e desempenho financeiro está de acordo com estudos realizados anteriormente, como o de Epstein e Roy (2003), Hess (2003), Yachin et al (2006), Ceres-ACCA (2007) e Wajnberg e Lemme (2009).

Cabe ressaltar a liderança das que compõem o subsetor de energia elétrica, que ocupam as primeiras classificações nos rankings de associação entre desempenho ambiental e financeiro. Além disso, este subsetor se apresentou como o de maior incidência de informações de caráter monetário referentes aos benefícios provenientes de ações ambientais, embora deva ser considerado que ele era o de maior número de empresas na amostra.

No que diz respeito às fontes de dados, duas características devem ser ressaltadas:

1) o porte aparentemente exagerado dos relatórios de sustentabilidade analisados, sugerindo que poderiam ser menores e melhores, concentrando-se na estratégia empresarial para sustentabilidade e nos principais resultados alcançados ou planejados, buscando sempre algum vínculo com a cadeia de valor;

2) as áreas dos websites das empresas que indicavam alguma relação com ações ambientais e relações com investidores não apresentavam informações ambientais adicionais aos relatórios de sustentabilidade, aspecto também citado no estudo feito por Wajnberg e Lemme (2009) sobre o setor bancário.

Apenas 5\% de todas as informações ambientais categorizadas nesta pesquisa eram monetizadas e relacionadas aos benefícios financeiros corporativos, estando, portanto, associadas a uma justificativa de negócios. Diante deste quadro, cabe questionar os motivos que podem justificar esta baixa associação com o desempenho financeiro corporativo.

Uma possibilidade, segundo Wajnberg e Lemme (2009), seria o fato de as práticas sustentáveis não serem economicamente atrativas e seus gestores as enxergarem apenas como capazes de agregar valor à marca e à reputação da empresa, não havendo necessidade de obter retorno financeiro no curto prazo e nem de divulgar informações financeiras a elas associadas. Outra explicação poderia ser que as empresas consideram estratégicas as informações sobre os benefícios financeiros provenientes das iniciativas sustentáveis e, por isso, não têm interesse em divulgá-las. Uma terceira alternativa seria considerar que as empresas ainda não conseguiram definir procedimentos e métodos que permitam quantificar financeiramente os efeitos de suas ações sustentáveis.

Cabe destacar, entretanto, que em diversos pontos dos relatórios ou websites analisados existiam diversas informações quantitativas expressas em natureza física ou operacional, que poderiam, com pouco esforço, ser transformadas em informações monetárias referentes aos benefícios decorrentes das ações ambientais, passando a estar, portanto, diretamente atreladas ao desempenho financeiro corporativo. Exemplos destas informações são as quantidades de energia ou água economizadas, a redução no consumo de materiais utilizados na produção ou administração e a quantidade de resíduos reciclados e comercializados. Isto sugere que as empresas perdem oportunidades de divulgar informações possíveis de serem transformadas em valor, indicando que, talvez, não tenham como objetivo apresentar o valor monetário de suas iniciativas sustentáveis e

Revista de Gestão Social e Ambiental - RGSA, São Paulo, v. 5, n. 2, p. 63-78, mai./ago. 2011. 
sim aparecer como praticantes de iniciativas conhecidas como politicamente corretas, situação dificilmente sustentada no longo prazo ou em períodos de dificuldade financeira ou crise econômica.

Segundo Mabler et al (2009), as empresas que não apresentam justificativas de negócios para suas práticas de sustentabilidade, não incorporam estas práticas em sua estratégia corporativa e defendem seu foco em sustentabilidade apenas como uma estratégia de marketing necessitam redirecionar seus investimentos para áreas mais rentáveis, uma vez que o gasto com sustentabilidade apenas por imagem não será compensado.

Um dos questionamentos sugeridos ao longo do desenvolvimento desta pesquisa diz respeito ao efetivo público-alvo da divulgação das práticas corporativas sustentáveis e à dificuldade de atribuir valor às práticas ambientais. A utilização de linguagem e informações não voltadas para os gestores de recursos e investidores profissionais impede uma clara associação entre meio ambiente e valor, dificultando uma correta alocação de recursos e a efetiva atribuição de valor adicional às empresas que praticam ações realmente diferenciadas e vinculadas à cadeia de valor e ao modelo de negócio.

Há necessidade de aprimoramento dos relatórios de sustentabilidade e dos websites, no sentido de estabelecer maior associação entre iniciativas ambientais e desempenho financeiro, apresentando uma justificativa de negócios para as práticas ambientais, por meio de relatórios mais concisos, com informações objetivas e direcionadas também aos agentes responsáveis pela atribuição de valor às ações ambientais corporativas. Esta visão aparece em pesquisas anteriores como as de Carpentier, Patterson e Malthouse (2003), Reppeto e Austin (2000), Gasparino e Ribeiro (2007) e Figge et al (2006).

Avanços nesta direção poderão ser obtidos com a separação entre ações voltadas para atividades-meio ou atividades-fim, além da apresentação das informações essenciais em reduzido número de páginas, remetendo o leitor interessado em mais detalhes para outras fontes de informação da empresa. Uma possível recomendação para as empresas seria designar um "redatorchefe" para seus relatórios de sustentabilidade, com bom trânsito nas diversas áreas da empresa, assegurando limitação de páginas e materialidade da informação, com clara definição do públicoalvo dos relatórios.

\section{REFERÊNCIAS}

A Global Reporters Research Publication 2008. The road to credibility: a survey of sustainability reporting in Brazil. SustainAbility Ltd., 2008. Recuperado em 12 abr.2009, de <http://www.sustainability.com/downloads_public/insight_reports/The_Road_to_Credibility_G R08.pdf.

Arx, U., Ziegler, A.(maio 2008) The effect of csr on stock performance: new evidence for the USA and Europe. Economics Working Paper Series. CER-ETH Zurich, Center of Economic Research at Eidgenossische Technische Hochschule Zurich. Swiss Federal Institute of Technology Zurich. Maio, 2008. Recuperado em 22 abril 2009, de <Social Science Research Network: < http://ssrn.com/abstract=1102528>

Brito, B. M. B. (2005) A reação do mercado acionário brasileiro a eventos ambientais. Dissertação (Mestrado em Administração) - Instituto Coppead de Administração, Universidade Federal do Rio de Janeiro, Rio de Janeiro, Brasil. 
CARPENTIER, C. L.; PATTERSON, Z.; MALTHOUSE, J. Environmental Disclosures in Financial Statements: new developments and emerging issues. New York: NEP FI, 2003.

Cavalcante, L.R., Bruni, A.L., Costa, F.J. (jan-abr, 2009) Sustentabilidade empresarial e valor das ações: uma análise na Bolsa de Valores de São Paulo. RGSA - Revista de Gestão Social e Ambiental.[S.1.], 3( 1), 70-86.

Ceres-Acca. Ceres-ACCA North american awards for corporate sustainability reporting: report of the judges. 2007. Recuperado em 19 abr.2009, de <http://www.ceres. org//Document.Doc?id=330> .

Cohen, M.A., Fenn, S.A., Konar, S.(1997) Environmental and financial performance: are they related? Washington. Investor Responsibility Research Center. Recuperado em 19 abril 2009, de $<\mathrm{http}: / /$ sitemason.vanderbilt.edu>.

Delai, I., Takahashi, S. (jan-abr, 2008) Uma proposta de modelo de referência para mensuração da sustentabilidade corporativa. Revista de Gestão Social e Ambiental, [S.1.], 2(1), 19-40.

Deloitte Touche Tohmatsu Brasil.(2009) A cadeia da sustentabilidade: uma pesquisa sobre visões e práticas de empresas brasileiras que impactam o futuro do planeta. Recuperado em 21 abril 2009, de. <http://www.deloitte.com/dtt/cda/doc/contentcadeia\%20de\%20sustentabilidade2.pdf>.

Epstein, M.J., Roy, M.-J. (2003) Making the business case for sustainability. linking social and environmental actions to financial performance. Journal of Corporate Citizenship, [S.1.], 9, 7996.

Feldman, S.J., Ameer, P., Soyka, P.A. (1996). Does improving a firm's environmental management system and environmental performance result in a higher stock price? Fairfax: ICF Consulting, 1996, 23p. Recuperado em 19 abr.2009, de <http://www.icfi.com/Publications /doc_files/resp_pays.pdf >.

Figge, F. et al.(2006) Sustainable value of european industry: a value-based analysis of the environmental performance of european manufacturing companies. ADVANCE Project.

Gasparino, M. F., Ribeiro, M. S. (jan-abr. 2007) Análise de relatórios de sustentabilidade, com ênfase na GRI: comparação entre empresas do setor de papel e celulose dos EUA e Brasil. Revista de Gestão Social e Ambiental, [S.1.], 1(1), 102-115.

Hess, H-J. CSM/WWF (2003) Research project: the business case for sustainability: financial services report. working paper series. Lausanne: CSM/IMD. Recuperado em 19 abril 2009, de $<$ http://www.imd.ch/research/centers/csm/upload/>.

Jacobs, B.W., Singhal, V.R., Subramanian, R. An empirical investigation of environmental performance and the market value of the firm. Social Science Research Network, Recuperado em 22 abril 2009, de: 〈http://ssrn.com/abstract=1320721>.

Klassen, R. D., Mclaughlin, C. P.(1996). The impact of environmental management on firm performance. linthicum: institute for operations research and the management sciences, Management Science, [S.1.], 42( 8). 
Knox, S., Maklan, S., French, P. (2005) Corporate social responsibility: exploring stakeholder relationships and programme reporting across leading FTSE companies. Journal of Business Ethics, [S.1.], 61, 7-28.

Kreander, N. et al. Evaluating the performance of ethical and non-ethical funds: a matched pair analysis. Glasgow: University of Glasgow, 2000, 35p. Recuperado em 19 abril 2009, de <http://www.departments.bucknell. edu/management/apfa/Dundee\%20Papers/42Kreander.pdf>.

Mabler, D. et al.(2009) Green winners: the performance of sustainability-focused companies during the Financial Crisis. A.T. Kearny, Chicago. Recuperado 21 abril 2009, de <http://www.svtgroup.net/pdfs/Green_Winners \%20AT\%20Kearny.pdf>.

Nossa, V.(2002) Disclosure ambiental: uma análise do conteúdo dos relatórios ambientais de empresas do setor de papel e celulose em nível internacional. $249 \mathrm{f}$. Tese (Doutorado em Controladoria e Contabilidade ) - Universidade de São Paulo, São Paulo, Brasil.

Reppeto, R.; Austin, D. (2000) Pure profit: the financial implications of environmental performance.. Washington: World Resources Institute. Recuperado em 19 abril 2009, de $<$ http://www.socialinvest.org/pdf/research/Moskowitz/2000\%20Winning\%\%20$\% 20$ Moskowitz.pdf>

Santaló, J., Kock, C. (2006) Investor's perception of value creation in environmental strategies: the impact of past environmental performance on future stock market returns. Instituto de Empresa, María de Molina 12 - 4o, Madrid, Espanha.

Sustainability, FBDS e UNEP, 2008. Rumo à credibilidade: independência e integridade do projeto. Recuperado em 24 abril 2009, de <http://www.fbds.org.br/Metodologia_Rumo _a_Credibilidade_abr09.pdf $>$.

Unep FI Australasian Advisory Committee On Insurance. (Janeiro de 2003). Risk, the environmental and the role of the insurance industry. EPA Victoria. Recuperado em 21 abril 2009, de http://www.environment.gov.au/settlements/industry/publications/pubs/riskinsurance.pdf.

Yachin \& Associates; Sustainable Investment Group; Corporate Knights. (2006) The sdEffect: translating sustainable development into financial valuation measures. a pilot analytical framework. Recuperado em 19 abril 2009, de <http://www.sdeffect. com/sdEffectFeb2006.pdf>.

Wajnberg, D., Lemme, C. F. (jan-abr,2009) Exame da divulgação do relacionamento entre iniciativas socioambientais e o desempenho financeiro corporativo nos bancos brasileiros. Revista de Gestão Social e Ambiental, [S.1.], 3(1), 53-69.

Data do recebimento do artigo: 19/07/2011

Data do aceite de publicação: 28/08/2011

Revista de Gestão Social e Ambiental - RGSA, São Paulo, v. 5, n. 2, p. 63-78, mai./ago. 2011. 